\title{
Time-use and well-being impacts of travel-to-work and travel-for-work
}

\author{
Daniel Wheatley and Craig Bickerton
}

\section{Version accepted in New Technology, Work and Employment $8^{\text {th }}$ October 2016}

\begin{abstract}
This article contributes to understanding of the complex patterns of travel-to-work and travel-for-work which increasingly characterize highly skilled employment, using 2015 data from a UK Midlands study comprising an online survey and follow-up interviews. Travel-to-work essentially lengthens the working day, and is difficult to use productively, especially when commuting by car. Travel-for-work, by contrast, results in intense schedules especially when requiring overnight stays. Ownership of travel-for-work is ambiguous: it is employer driven, and travel time is often spent productively using mobile technologies, but is rarely rewarded with TOIL. While general dissatisfaction is reported with the commute, negative effects of travel-for-work (family, health, reduced leisure time) are mediated by positive impacts including experience of new working cultures, and infrequency of travel. Four factors appear central to the differing well-being impacts: (1) frequency of travel; (2) ability to plan travel; (3) productive use of travel time, and; (4) reciprocal benefits of travel.
\end{abstract}

Keywords: highly skilled workers, subjective well-being, time-use, mobile working, travelfor-work, travel-to-work.

JEL Classification: J22, J28, I31, R41.

\section{Introduction}

This article contributes to our understanding of the complex patterns of travel-to-work and travel-for-work which increasingly characterize highly skilled employment, specifically employment in managerial, professional and associate professional occupations. Highly skilled employment is used to refer to employment in managerial, professional and associate professional and technical occupations in this article, using UK Standard Occupational Classification definitions. There is no consistent definition for what constitutes a highly skilled occupation or individual, although attempts have been made to classify workers as 
highly skilled based on higher education, occupation, and income level (see Chaloff and Lemaître, 2009, 11; Mahroum, 2000). It should also be noted that managerial, professional and associate professional occupations are themselves distinct in nature. For a discussion of the conceptual and empirical differences see, for example, Wheatley et al (2011). Workers in these occupations report some of the most complex patterns of travel-to-work, and are some of those most engaged in travel-for-work (Lassen, 2009; Wheatley, 2014).

Travel-to-work, the commute, acts as a bridge between home and work and can be considered to be necessary work-related time-use (Wheatley and $\mathrm{Wu}, 2014,449$ ). The commute varies in distance and complexity throughout the life-course, incorporating at certain stages activities linking travel and family e.g. the 'school run'. This time-use is perceived as both 'productive' and a 'waste of time' (Basmajian, 2010, 76). The commute is often particularly complex for highly skilled workers who are expected to demonstrate high levels of mobility, but may face difficulties where household responsibilities are present, or both partners in households pursue careers creating tension over residential location decisions (Wheatley, 2014). Travelfor-work, is work-related travel, including (inter)national business travel, certain forms of teleworking, and working at multiple workplace locations, which is undertaken in order to fulfil tasks of employment. Amongst other things, it is used to meet and work with clients, suppliers and colleagues, undertake training, attend and participate in conferences/exhibitions, and work at customer sites (Nicholas and McDowall, 2012, 336). It is not usually used to refer to short trips e.g. a meeting taking place within the same urban area (Jones, 2013, 63). Travel-for-work has become increasingly common, especially among highly skilled workers, driven by sectoral and technical change, and the increasingly unbounded nature of paid work (Jeong et al, 2013, 150; Gustafson, 2006, 522). Travel-forwork can be stimulating and rewarding, offering workers a range of potential benefits 
(Gustafson, 2014, 70-1). It differs from the commute as it can be irregular, and involve periods of absence, and presents travellers and their households with a range of specific challenges and benefits (Nicholas and McDowall, 2012; Gustafson, 2006, 2014). Difficulties may be faced in achieving desired mobility, though, as a result of obligations at both home (e.g. children, ill/elderly relatives/friends) and work (e.g. workloads).

The impacts of these forms of work-related travel, including reported subjective well-being — referring to self-assessment of an individual's overall well-being (Diener et al, 1999) — is therefore important to our understanding of highly skilled workers' routines of work and time-use. In the absence of suitable large-scale secondary data, the article draws on primary data collected from a mixed methods research project conducted in the UK Midlands in 2015. This article specifically explores how time spent travelling to, and for, work is used, and how highly skilled workers perceive this time-use, as well as reflecting on the impacts of patterns of travel-to-work and travel-for-work on the time-use and well-being of highly skilled workers.

\section{Work and travel: mobility, blurred boundaries and complex time-use}

It has been argued that human movements should not be segmented conceptually into strictly demarcated categories. Mobility is better understood as spanning a continuum that ranges from simple everyday movements including commuting, through longer time-distance movements including travel-for-work, to unbounded activities including virtual mobility (Pooley et al, 2005, 2-3). Paid work has become increasingly characterized by high levels of mobility, especially among highly skilled occupations, rendering paid work better understood as an 'activity' rather than 'place' (Felstead et al, 2005). These changes have been driven by technical change including ICTs and mobile technologies, globalization, organizational 
trends including working in project teams, and inter-firm cooperation and knowledge sharing (Aguiléra, 2008; Felstead et al, 2005; Hislop and Axtell, 2009).

The commute has increased in time-distance as availability of travel by train from the $19^{\text {th }}$ Century and by car since the 1960s have enabled workers to travel further to work (Pooley et al, 2005, 114). Commutes for the majority of workers, though, remain in the form of frequent, often daily, journeys over relatively short distances (Green and Owen, 2006). The 2015 UK National Travel Survey calculates average individual commutes at 31 minutes per journey (ONS, 2016). The car remains the dominant mode of transport to work in the UK as it remains perceived as the most flexible and convenient (Eriksson et al, 2013). The commute, though, can create a number of challenges. While workers, in principle, have a level of control over the time and distance they commute, this choice is subject to constraints associated with local employment opportunities, working routines (including hours of work, flexibility and employer demands), residential housing markets, geography, and the commutes of others within the household (Green, 2004, 636; Sandow, 2008). In households where both partners are engaged in paid work, particular challenges are faced in combining two commutes often to different locations. As a solution households may locate their residence close to transport hubs/nodes (Kloosterman and Musterd, 2001, 625), however this can result in longer commutes. Partners unable to find two jobs in a preferred location will compromise, though compromise is often greater on the part of women potentially limiting their mobility (Green, 2004, 636; Wheatley, 2014).

Facilitated by technical developments, including faster transportation networks which render frequent long distance, and international, travel feasible, there has also been a considerable growth in recent decades of travel-for-work including (inter)national business travel 
(Aguiléra, 2008; Bergström Casinowsky, 2013, 311). Travel-for-work requires both temporal and spatial availability. Availability in this context refers to the ability of a worker to respond to employer demands (Bergman and Gustafson, 2008, 193-4) which may be impacted by other demands on their time-use including family. The ways in which labour markets are structured and operate often results in workers taking on roles that may not match their preferences, including those over travel-for-work. Some employers exert institutional pressure' on workers to be mobile (Lassen, 2009). In some cases workers report a travel 'threshold', reflecting the notion of a minimum amount of travel perceived by the worker as necessary to be successful, in particular through the generation and maintenance of networks (Storme et al, 2013, 16-17). Where more frequent travel assignments are present, though, travel-for-work creates complications including uncertainty over short-term work location (Bergman and Gustafson, 2008, 192).

Organizations may include business travel within a broader 'travel plan', including the provision of alternatives e.g. virtual meetings via internet, video, or telephone (Cairns et al, 2010, 891; Gustafson, 2012). Despite developments in ICTs, though, there remains demand from employers, driven in part by client demand, for face-to-face contact in order to build personal relationships and create mutual trust (Aguiléra, 2008). Certain tasks may be more effectively completed through face-to-face interaction e.g. providing feedback (Boell et al, 2016, 126). Face-to-face contact, though necessitates greater amounts of travel.

Survey data provides insight into the nature and the extent of travel-to-work and travel-forwork in the UK. The 2015 UK National Travel Survey identifies that while business travel only accounts for approximately 3 per cent of total journeys, this represents 9 per cent of total distance travelled and around 16 per cent of long distance journeys (ONS, 2016). Meanwhile, 
data from the 2015 International Passenger Survey, revealed that 10.9 per cent of travel overseas by UK residents, and 24.5 per cent of inward travel to the UK, are for business (ONS, 2016a). Annual expenditure on business travel is considerable. In 2015 it was estimated at approximately USD 1.25 tn globally. UK spending on business travel is the second-highest in Western Europe, reaching £30.8bn in 2015 (Global Business Travel Association, 2016).

Similar to patterns observed in commuting, gender also plays an important role in determining the ability and willingness of individuals to travel. US data suggests that men display greater availability for, and frequency of, travel-for-work, and that married men in particular are more likely to undertake frequent travel (Jeong et al, 2013, 148-9). Presence of children may increase travel among men especially where they are the primary earner within their household as they are under greater financial pressure, increasing their willingness to respond to employer demands. Meanwhile, women more often become more closely tied to home reducing incidence of travel (Gustafson, 2006, 523). The UK National Travel Survey reveals a consistent pattern in the UK as men, in particular those aged 40-59, most frequently travel for work (ONS, 2016). Family responsibilities mean women who do undertake travelfor-work are more likely to avoid overnight stays, but this can result in intense work routines as travel to and from the destination is performed on the same day (Bergström, 2006).

\section{Productivity and ownership of travel time}

Work-related travel time can be used productively, providing workers with time to work with a level of autonomy away from the office. One study, for example, showed that 50-60 per cent of employees work during business travel (Holley et al, 2008). Employees engage in a wide range of tasks while working on the move (Koroma et al, 2014, 149). Recent research 
highlights the importance of the nature of work tasks to the ability to work on the move. Certain tasks are more suited than others to working on the move or remotely, although it is also found that the relative suitability of tasks to mobile working can differ between individuals and workplace teams (Boell et al, 2016, 125-6). The productive potential of both the commute and travel-for-work is dependent on a range of factors, including mode of transport, time of day, and length of journey, as well as travellers own preferences and choices regarding how they spend travel time (Gripsrud and Hjorthol, 2012; Holley et al, 2008). Train travel appears to provide the greatest potential for productive 'working' travel time, as it involves relatively less 'unusable' waiting time compared to air travel, lesser personal input, and is less stressful than car travel (Gustafson, 2012a). The loss of useful time, though, resulting from time spent travelling intensifies both work and family time, as high workloads and mobile work routines limit time available for family and friends prompting travellers to use this time efficiently (Gustafson, 2014, 73). Holding virtual meetings using ICTs may allow workers to avoid travel. However, virtual meetings may enhance opportunities to extend existing and forge new relationships which, in turn, can increase the demand for travel (Lu and Peeta, 2009).

One of the central concerns surrounding time spent commuting and travelling-for-work is one of ownership. There exists no clear divide between the 'work-time' owned by the employer, and 'leisure time' owned by the worker (Holley et al, 2008). While both travel-to-work and travel-for-work are not considered 'work-time', travel time may be used productively. With respect to travel-for-work, frequent travellers are often in managerial and professional occupations where remuneration is based on task completion rather than the number of hours worked (Gustafson, 2012a, 215), which adds to the complexity of what constitutes and defines 'work time'. While employers may not have expectations regarding completion of 
work while travelling (Gustafson, 2012, 214; 2014), time 'lost' travelling is rarely compensated in regard to reductions in workload (Espino et al, 2002; Gustafson, 2006). Meanwhile, many workers use travel time to complete work tasks in order to avoid having to complete this work on their return, although the ability to work using mobile technologies could result in employees being given greater workloads. Indeed, workers undertaking travelfor-work report greater incidence of working longer than usual or expected hours, and bringing work home (Bergman and Gustafson, 2008, 201), while travel may increase difficulties surrounding schedule inflexibility reducing the ability of workers to manage competing role demands (Bonache, 2005).

In some cases, completing tasks while travelling-for-work represents the only opportunity for employees to avoid the invasion of work demands into family and leisure time (Gustafson, 2014, 71). Lengthy travel-for-work may require time off afterwards in order to allow for recuperation (Espino et al, 2002, 314). Some employers allow time off or working from home on an informal basis (Gustafson, 2012a), although the formal provision of time-off-in-lieu (TOIL) may not be as common. Workers may seek to gain recognition of business travel time as 'work-time', but doing so could come at a significant cost to autonomy. Most workers would not wish their employer to engage in the recording and monitoring of work-time. While not recognised through TOIL, travel-for-work may be rewarded in other ways. Income is positively associated with both the occurrence and frequency of travel-for-work, in part because of greater incidence of travel among those in highly skilled and senior occupations (Jeong et al, 2013, 150; Gustafson, 2006, 522). Willingness and availability to travel may, though, provide greater promotion prospects (Gustafson, 2006, 527; 2014, 74). International travel, in particular, may improve career prospects through skill acquisition and personal development (Bonache, 2005). Research has also suggested that international business travel 
is often equated with higher social status, while travellers develop a more 'cosmopolitan' identity as they are exposed to, and interact with, different cultures (Lassen, 2009).

\section{Subjective well-being effects}

A range of aspects of travel can affect well-being. These include the ability or potential of an individual to travel which is linked to access to transport and residential location amongst other factors, mode of transport, activities undertaken while travelling including mobile working, participation in work or leisure enabled by travel, and movements for leisure purposes where this activity acts as a source of utility e.g. recreational cycling (De Vos et al, 2013; Moktharian and Solomon, 2001). While research has considered the subjective wellbeing effects of travel-to-work (see for example De Vos et al, 2013; Ettema et al, 2012; Roberts et al, 2011; Wheatley, 2014) there is an absence of research which focuses on travelfor-work. Studies rooted in the psychology discipline have considered the impacts of travelfor-work in regards to stress and impacts on couple's relationships, but studies have not examined the broader time-use and subjective well-being effects.

Travel-to-work is often perceived as a source of dissatisfaction. Research has shown that the commute represents one of the least appreciated activities performed during the day (Kahneman et al, 2004; Wheatley, 2014). Lengthier commutes may reduce life satisfaction, off-setting benefits individuals receive from attractive residential locations distant from their workplace (Stutzer and Frey, 2008). Evidence suggests that workers exhibit a time limit beyond which they are unwilling to commute, referred to as a 'commuting tolerance'. Empirical observations suggest a 'tolerance zone' in the range of about 30-45 minutes (Clark et al, 2003, 200). Other recent research (Ettema et al, 2012, 219-20), though, has identified that commutes can be viewed positively, although relative satisfaction is associated with 
mode of transport, stress levels, boredom/other negative feelings, and exogenous factors (e.g. road maintenance). The well-being effects of the commute may be particularly influenced by the extent to which it is perceived by the individual to be productive (Basmajian, 2010; Gripsrud and Hjorthol, 2012), although conflicting evidence is found (Ettema et al, 2012). Gender differences in impacts have also been suggested. For example, the commute may have more detrimental effects on women as a result of their greater household contribution, including childcare and housework (Roberts et al, 2011, 1071).

Workers may derive satisfaction from travel-for-work through using travel time as an opportunity for 'relaxation' and respite from the pressures and demands of both the workplace and home and family. Some workers actively choose not to complete work during travel, although they may use this time to think and plan work (Gustafson, 2012a, 210). Evidence suggests, though, that many workers do make productive use of travel-for-work to complete work without distractions present in the workplace. Understanding what tasks can be completed where is central to the successful management of travel time (Felstead, 2012, 36). While workers may make productive use of travel time, and even enjoy travel, minimizing travel and overnight stays often remains a priority. These decisions are driven by family responsibilities, social obligations and leisure preferences (Gustafson, 2012a, 216). Travel-for-work can be stressful and may reflect increasing demands from employers for workers to be available for work (Bergman and Gustafson, 2008). Espino et al $(2002,312)$ reported that 74 per cent of a sample of World Banking Group employees reported high or very high stress levels associated with travel-for-work. Work-related stress can result from planning and preparation for travel, practical problems including delays, cultural differences, health and safety concerns during travel and at the destination including exhaustion from travelling and problems sleeping, poor diet and difficulty exercising while away, accumulated 
work following a return from travel, and feelings of isolation (Espino et al, 2002, 318). Mobile workers are alone while travelling and feel neither a part of the workplaces they visit nor their main workplace. As a result travellers can suffer from a lack of support and feelings of being marginalised (Koroma et al, 2014, 150). Travellers do, though, report developing 'travel competence' strategies in order to mediate some of the negative impacts of travel, for example taking only hand luggage, and carefully choosing an airline (Gustafson, 2014, 70). Storme et al $(2013,15)$, investigating the travel behaviours of a sample of academics, find that while approximately 30 per cent undertake little, and often relatively local travel, the majority of academics do travel regularly for work and are able to manage travel alongside work and home obligations.

Increased travel-for-work has been associated with work-family conflict and marital difficulties (Roehling and Bultman, 2002). Challenges are faced when working flexibly in multiple locations as leisure time is reduced, which negatively affects satisfaction with leisure (Wheatley, 2012, 233). Absences from home, especially if frequent, may result in stress and psycho-social problems among both travellers and their families (Black and Jamieson, 2007). Travel-for-work may be particularly stressful for those with children and for the children of workers undertaking travel-for-work (Espino et al, 2002, 316-8). Significant impacts may be felt, especially for the traveller, on the quality of daily interactions, subjective stress, and sleeping problems/physical symptoms, although the relative impact of travel-for-work may differ at the individual level (Diamond et al, 2008). In addition, Gustafson (2014, 72) suggests that frequent travel can cause feelings of separation and loneliness. Meanwhile, the impacts of travel continue after the travellers return. As a result of the time-squeezing effects of travel-for-work, travellers with families tend to prioritize their families when returning from travel. Frequent travel-for-work therefore constrains, in particular, the time available for 
social and leisure activities, especially in relation to 'collective activities', including social events or organized leisure activities with friends/relatives (Gustafson, 2014, 73). Overall, the extant literature provides evidence of widely negative impacts associated with the commute. Meanwhile, the evidence suggests that workers 'make the most' of travel-for-work, but that this activity requires careful management.

\section{Data and method}

Large-scale national data-sets collected within the UK, while offering useful evidence on patterns of travel-to-work (e.g. Labour Force Survey) and business travel (e.g. National Travel Survey), do not currently capture patterns of work-related travel and responses regarding impacts, including well-being effects. A mixed method primary data collection exercise was, therefore, conducted in the UK Midlands in 2015. The project explored patterns of travel-to-work and travel-for-work among highly skilled workers. The sample was drawn from the both the East and West Midlands regions. These regions combined provide a sample which is representative of other UK regions, excluding London, in industrial and occupational breakdown, hours worked, and travel-to-work patterns (Green and Berkeley, 2006; Hardill et al, 2006).

Primary data was collected from a sample of highly skilled workers in UK Midlands-based organizations from private, public and voluntary and community sectors using an online survey. Particular focus was given to patterns, and impacts, of travel including capturing qualitative responses through a series of open questions. The survey received a total of 141 responses (after the removal of invalid/incomplete responses) from 70 different organizations, ranging from SMEs to large multinationals. The sample comprised a representative gender balance (61.4 per cent men), consistent overall with patterns of 
employment in highly skilled occupations (Wheatley and Wu, 2014). The average age of the men and women sampled was 46.3 and 40.4 respectively, and approximately 48 per cent of respondents reported dependent children. Around 90 per cent of the sample reported working full-time, and 72.3 per cent worked in the private sector. All reported employment in highly skilled occupations.

The second phase of the project involved collecting data through follow-up semi-structured interviews using a stratified 10 per cent sub-sample of the survey, comprising 14 highly skilled workers. The interview sample provided a cross-section of workers by gender, age and travel patterns, offering insight into travel-to-work and travel-for-work among those with family responsibilities, in different occupations and career stages. Profiles of the interviewees are provided in Table 1. A thematic coding method (Ritchie and Spencer, 2003) was used to analyse the interviews.

TABLE 1 HERE

The analysis offers specific consideration of subjective well-being effects. A stated preference measure, subjective well-being is usually derived from survey questions of the form 'All things considered, how satisfied are you with your life as a whole these days?', where responses are given on a Likert scale usually comprising either five, seven, or eleven categories ranging from 'not at all' or 'completely unsatisfied' to 'completely satisfied' (Hicks et al, 2013, 78). The well-being impacts of travel are explored in this article through the question, 'How does your commute/travel-for-work impact the following aspects of your life?', with responses pertaining to career, time-use, family, health and general happiness 
given on a 5 -point Likert scale where $1=$ strong negative, $3=$ neither positive or negative, and $5=$ strong positive.

\section{Empirical analysis: complex patterns of work-related travel}

Broadly consistent with patterns observed in the UK among highly skilled workers (e.g. McQuaid and Chen, 2012, 167), average home to work travel time among the survey sample was reported as 35.9 minutes with men reporting longer commutes averaging 37.5 minutes compared to 33.4 minutes for women. The majority of respondents reported travelling-towork by car (74.5 per cent), while slightly less than 8 per cent of respondents and slightly more than this number travelled by bus and train respectively, and the remainder walk or use a tram. Practicality and accessibility are the key determinants of employees' choice of mode of transport: 'I always drive, where I work it isn't easily-accessible by public transport. To go by train would take several trains, the same by bus, and I live too far away to cycle.' [Interviewee 5]. Acknowledgement was made of the role of residential location, including the challenges associated with housing markets and how households in some cases compromise over residence where both partners pursue careers (Green, 2004, 636; Wheatley, 2014): 'Ultimately I think what we need to do is think about where we're based and whether we could be based somewhere else, so that it works better for all of us. But as things stand it's just a very difficult time to move.' [Interviewee 10]

The most common forms of travel-for-work reported among the survey sample were ' 1 day (no overnight stay)' reported by 62.1 per cent of respondents, followed by '2-3 days (requiring overnight stay)' reported by 23.4 per cent of respondents. The bulk of respondents

(77.4 per cent) reported travelling locally, regionally and nationally as part of their job. Meanwhile, 27.0 per cent reported travelling internationally within the EU, and 18.5 per cent 
internationally outside of the EU. Purposes of travel-for-work included: generating new business (reported by 46.8 per cent of respondents); meeting with clients (56 per cent); meeting with project teams (43.3 per cent); visiting other sites within the organization (37.6 per cent); training (47.5 per cent), and attending conferences (58.2 per cent). Approximately 60 per cent of respondents reported usually travelling by car, either their own or from rental or carpool, while 24 per cent travel by train, and 10 per cent mostly by air. Consistent with existing evidence (Jeong et al, 2013, 189-9; ONS, 2016), frequent travel is more common among men, and their travel is also more likely to include overnight stays. Almost one-inthree men surveyed reported travelling at least weekly for work, compared to one-in-ten women. Almost two-thirds of employers have formal policies pertaining to travel-for-work. Almost three-quarters of respondents reported organizing their own travel arrangements, although many employers require use of a company travel agent. A number of respondents reported an explicit preference to retain control over travel arrangements. As one male survey respondent, aged 32, a principal lecturer who undertakes frequent travel-for-work within the EU commented: 'I arrange it to ensure [a] level of control over timing and method of travel and overall length of time away.’ [Survey Respondent 102].

\section{Travel impacts and subjective well-being effects}

Table 2 summarizes mean responses and correlation coefficients pertaining to the impacts of the commute and travel-for-work. It is evident that time spent commuting has negative impacts on time-use, family, health and overall happiness. The correlation coefficients also indicate negative impacts that are exacerbated by the time-distance of the commute. This finding is consistent with the notion of a commuting 'tolerance' (Clark et al, 2003), with lengthier commutes generating more negative impacts. The impacts of travel-for-work, measured with reference to both frequency of travel and the number of nights spent away in 
the 12 months prior to survey, suggest that frequency of travel, but more significantly overnight stays away from home, are important. Travel-for-work has particular negative impacts on family and health, while effects also spillover into overall happiness where frequent overnight travel is undertaken. In contrast with the commute, travel-for-work is correlated with certain positive impacts, specifically on career where more frequent overnight travel is reported. It is also noteworthy that no direct correlation is found in the survey sample between commuting time and travel-for-work frequency. Indeed, a number of factors including residential location impact the length of the commute, whereas patterns of travelfor-work are driven more by occupation and industry of employment.

\section{TABLE 2 HERE}

Travel-to-work: qualitative evidence

The majority of the interviewees viewed the commute as a 'waste of time' (Basmajian, 2010, 76), especially when travelling by car. The commute has particular impacts on time-use, as reflected in Table 2. The commute is seen to curtail available leisure time: 'It does limit leisure time or the willingness to pursue further leisure because you're tired ... the real downside is your evenings are shorter and the opportunities to do things are restricted.' [Interviewee 14]. Stress and frustration are some of the most commonly reported feelings associated with commuting by car. Car travel is also subject to unplanned delays resulting in journey times varying considerably, creating frustration and wider impacts on family: 'I think [because] my commute has an impact on my daughter as well, it can be a little bit more stressful.' [Interviewee 12]. 
When travelling by car practical challenges are faced in using commuting time productively: 'Whilst you try to make it productive you kind of feel it's dead time, it's neither at work, or with the family.' [Interviewee 11]. Around one-in-five men, but one-in-ten women, reported regularly working during their commute. Among those working while travelling, 78.3 per cent reported use of mobile technologies. One interviewee further explained that by driving, the unproductive use of this time essentially lengthens the working day: 'I found when I was driving I was actually having to work longer hours to kind of catch up.' [Interviewee 4] Commuting time, though, can be used to think as one male survey respondent aged 55, a managing director with a 20 minute commute, reported: 'I cannot [work] when driving, although I do use the time to think about work, either planning the day ahead or reflecting on the day past.' [Survey Respondent 4]. Use of other methods of transport increase the productive potential of the commute:

'With public transport at least you can do things productive. So you can do an hour of work which is good [as] that time can mean that you're perhaps not then working ... into the evening.' [Interviewee 10]

The relatively short nature of many journeys by bus or train may, though, act as a barrier to undertaking tasks when commuting. Using the commute as a multi-activity journey, moreover, appears to exacerbate negative impacts, and these impacts are more often felt by women (consistent with Green, 2004, 636; Wheatley, 2014) as they predominantly perform the school-run and similar household tasks: 
'I tend to pick my little girl up on the way home ... It can obviously be quite stressful when I'm trying to fight my way through traffic to get to nursery on time.' [Interviewee 12]

Respondents also report negative impacts on their family which, consistent with the patterns observed in Table 2, appear most severe where lengthy commutes (over 60 minutes per journey) are reported:

'Some days you're working nine/ten-hour work days and then you add on another two hours [commuting], you're out of the house for a very, very long time. So quite often trying to see your partner might be quite difficult because of their working hours as well, sometimes by the time you get in and you've made dinner and done everything else you need to do, it can be quite late in the evening. So sometimes it can be very frustrating.' [Interviewee 5]

Some positive aspects of the commute were reported, including health benefits associated with particular modes of transport, specifically walking or cycling, and the commute providing a mental separation between work and home: 'On the days that I cycle in you know or walk, I just think it's good exercise, it's an opportunity to just get some fresh air' [Interviewee 8]. Notably, the majority of the more positive responses were reported among those not commuting by car, further evidencing the difficulties associated with the most common mode of transport. A 54 year old male survey respondent, employed as head of services at a City Council, who reported a 40 minute commute commented: 
'Travel by train with a walk at each end of the journey is far less stressful than driving in heavy traffic, [and is] much quicker and healthier' [Survey Respondent 126].

\section{Travel-for-work: qualitative evidence}

Travel-for-work has specific impacts on time-use. It is often undertaken outside of 'normal' working hours. Four-in-five respondents stated that they regularly travel outside of their usual hours of work. This travel can result in intense schedules:

'You're invariably working in the evenings as well in the hotel. So in terms of the hours in those weeks when you are away it is normally a lot more than you would do if you were in the office, because you're trying to get everything done.' [Interviewee 12]

Moreover, in some cases availability for travel may be equated with commitment by managers/colleagues, as a male technologist, aged 30, who reported regular international travel commented: 'Making the effort to travel is often noticed by my manager as putting in extra effort, especially as outside of normal hours, it is unpaid' [Survey Respondent 120]. However, travel-for-work travel time is rarely considered as 'work-time' by employers, nor is it rewarded with TOIL. Consistent with the extant literature (Espino et al, 2002; Gustafson, 2006) only 25.2 per cent of respondents report receiving TOIL, while even fewer report receiving additional pay (1.6 per cent) or other benefits/perks ( 6.3 per cent). A 45 year old female survey respondent employed as a senior investigator scientist in medical research observed: 'Travel is important for work, but it is also exhausting, and very often I have to travel outside normal work hours or over weekends with no TOIL' [Survey Respondent 87]. 
The lack of acknowledgement by employers of travel time as working time is important as this travel time is often used to complete work tasks. More than half of the survey respondents (59.8 per cent of men and 48.8 per cent of women) reported working when travelling-for-work. Travel time is used to complete various tasks as per Koroma et al's findings $(2014,149)$, including preparing for meetings (e.g. reading documents) (78.6 per cent), checking/sending emails (70 per cent), phone calls (60 per cent) and report writing (60 per cent). Over four-fifths of respondents reported using mobile technologies to complete work during travel (or waiting time). Travellers work as a way of passing time and using the time productively, in some cases to complete work that would be difficult in 'normal' working hours. Productive use of travel time does leave many workers feeling this time is not lost or wasted: 'Technology enables some of the time 'wasted' travelling to be useful' [Survey Respondent 4]. However, some respondents did report feeling that they were expected by their employer to work during travel and/or that this was necessary in order to avoid heavy workloads upon their return (Gustafson, 2014, 71). As a female manager, aged 34, who travels internationally for work reported: '[I] work during travel to maximise the time and to ensure I am being as efficient as possible. It also reduces any work that I may need to do at home.' [Survey Respondent 121].

Family is reported as being negatively impacted by travel-for-work, as travel limits time with family members and friends and can result in short-term periods of absence: 'The cost of having to travel for work is essentially less time at home.' [Interviewee 7]. Health also suffers, in particular among those reporting greater frequency of overnight stays, as a result of irregular sleeping patterns, poor diet, and being too tired/unable to exercise. As one 47 year old male chartered surveyor who reported frequent travel within the UK and Ireland 
commented: 'Health suffers because travel is sedentary, and the quality of food is lower than [at] home' [Survey Respondent 62]. Given these impacts, it is unsurprising that approximately half of the survey respondents (49.2 per cent) reported explicit preferences to avoid overnight stays wherever possible: 'Generally speaking, I would be happy to leave early and get back late rather than to stay away, I mean purely just for sort of family and domestic reasons, it's nice to ... at least if you get back late, you can be there the next morning.' [Interviewee 10]. Nevertheless, around 10 per cent of respondents spent at least a month (30 nights or more) away cumulatively during the 12 months prior to interview. Importantly, Table 2 shows that these workers report the greatest positive impacts from travel-for-work on career (mean of 4.2), but also report the most negative impacts on family (2.2), health (2.5) and overall happiness (2.7). In part overnight stays among more frequent travellers reflect practicality:

'Ideally if I was able to I'd be home every night but I think it would probably kill me ... I wouldn't be able to function with family or at work, so yeah it just wouldn't work.' [Interviewee 4]

Moreover time away is traded-off for positive features of travel-for-work. Travellers receive reciprocal benefits associated with career development (e.g. development of professional networks), and other 'added value' including exposure to different places and cultures, and opportunities to 'get out of the office'. A number of these benefits are particularly prevalent where more distant and frequent travel is involved requiring nights spent away from home:

'Travelling to different organizations and cultures, and meeting different people is stimulating and generates fresh thinking. This enhances career and overall 
happiness, at the expense of fatigue and absence from home' [Survey Respondent 4].

The lesser frequency of travel-for-work among most workers mediates the negative impacts in many cases, even where overnight stays are required: 'In a sense it probably has a less detrimental effect on family than commuting because you go away, there's the empty space and then you're coming back.' [Interviewee 10].

Overall, the evidence suggests both travel-to-work and travel-for-work have significant impacts on the time-use of workers, in particular in reducing time available for family and leisure. It is also important to note that a number of respondents noted some blurring between these forms of mobility. Nevertheless, important differences are observed. The ability to use travel time productively is evident in travel-for-work, as is the added value that workers derive from this travel, but using travel time productively is problematic during the commute, especially when travelling by car, rendering the impacts of these forms of travel distinct. Benefits are therefore perceived by those travelling-for-work, but are not associated with the commute:

'I think you feel valued in the sense of being asked to, and being allowed to make these trips, you feel that some value is attributed to you doing these things. Whereas you feel that there's no reciprocal sense if your commute is onerous or difficult. And of course obviously you choose where you work and well that's just tough you know.' [Interviewee 10]

\section{Discussion and conclusion}


This article has contributed to our understanding of patterns of travel-to-work and travel-forwork among highly skilled workers, using evidence from a study conducted in the UK Midlands in 2015. Existing research shows the commute generating widely negative impacts (Kahenman, 2004; Stutzer and Frey, 2008). The empirical analysis supports and extends existing research, evidencing in particular the practical challenges associated with using the commute productively given the continuing reliance on the car as the main mode of transport to work. The nature of the commute, and its link to decisions over residential location which influence the length of the commute and mode of transport, provides a rationale for it not to be considered work-time. However, it essentially lengthens the working day. The commute is, therefore, widely perceived as 'dead time', or a 'waste of time'. Negative impacts are particularly pronounced among those reporting lengthier commutes, as they reduce available leisure time, and time with family. Stress, associated mostly with travel by car, also has detrimental health effects. Where commutes are viewed more positively, use of alternative modes of transport are reported which provide health benefits (walking, cycling), and/or enable the commute to be used more productively (public transport, especially travel by train). Mode of transport does appear a key factor in determining the impacts of the commute (Ettema et al, 2012). These findings suggests there are real benefits to be had for workers where they are able to use an alternative to the car. Household responsibilities, especially among women (Wheatley, 2014), and lack of access to alternative modes of transport in some residential locations, however, limit options for many workers rendering the commute a widely negative experience.

Travel-for-work generates a number of similar negative impacts to the commute. However, the impacts of this travel are more nuanced. Existing literature identifies a number of benefits, including career development (Bergman and Gustafson, 2008; Gustafsen, 2014; 
Bonache, 2005). However, challenges exist for those travelling-for-work, including reduced time for family and socialising (Gustafsen, 2014), stress and work-family conflict (Roehling and Bultman, 2002; Black and Jamieson, 2007), and impacts on health (Espino et al, 2002, 318). The evidence presented in this article is consistent with a number of these impacts, as respondents report travel-for-work as providing opportunities to extend professional networks, gain exposure to other cultures, and 'get out of the office'. These benefits are especially pronounced among those reporting greater frequency of travel and overnight stays. Travel-for-work, though, can result in intense schedules. Planning becomes increasingly important to off-set negative impacts (Bergman and Gustafson, 2008; Gustafson, 2014). Workers also widely report that travel time is not recognised as work-time (or rewarded with TOIL or similar compensation). This time is nevertheless often used productively, aided by mobile technologies, as a way of passing time and avoiding work overload following return from travel. Some workers reported expectations from employers that they would work during travel, evidencing that the productive potential of this time may be translated into increased workloads as employers assume workers are available to work. Lengthier and/or more distant travel requiring absence from home provides the greatest opportunities to increase mobility capital and 'see the world', but at a potentially significant cost to family time, and personal health. Correlations between impacts and the number of nights spent away provide evidence of the compounding effect of more intense travel-for-work. Indeed, travellers report conscious attempts to minimize travel time and avoid overnight stays due to impacts on family, social lives, and leisure. The relative infrequency of travel-for-work among many workers mediates the impacts, but where travel, especially that requiring overnight stays, is reported frequently the impacts of this travel appear compounded. 
This article contributes to our understanding of work-related travel through identifying the attributes which distinguish the impacts of travel-to-work from travel-for-work. Four factors appear central: the frequency of travel, ability to plan travel, productive use of travel time, and reciprocal benefits of travel. The commute is frequent, and each journey requires little planning for the majority of workers who commute to the same or similar locations on a daily basis. The regularity of this necessary work-related activity, however, is actually a driver in its negative perception. The commute can be subject to unplanned delays, which increases stress through unexpected events/lost time (Ettema et al, 2012). Lengthy commutes, and in particular those that are stressful and/or inconsistent in nature, reduce relaxation/leisure time, and may leave individuals too tired to exercise. Mode of travel is also central as travel by car appears to exacerbate the negative impacts, and renders the commute unproductive. In contrast, while travel-for-work arguably has notionally greater impacts on time-use, at least in the short-term, it is less frequent and subject to greater planning in advance, more often by the traveller. Planned disruption of this nature is easier to manage. Travel time is also often used productively, facilitated by mobile technologies. Finally, workers report a conscious trade-off between the costs of absence from home and intense patterns of work, and the added value derived from travel-for-work including career and wider cultural and social benefits.

The evidence presented in this article is subject to certain limitations. The small scale of the research project reported, and focus on one group of workers, does render the findings limited in their generalisability. However, highly skilled workers report some of the most complex and demanding routines of work-related travel, and so offer important insight into the potential impacts of travel-to-work and travel-for-work. Further research could explore these issues through a larger-scale data collection exercise. In particular, exploring cross-nationally the ways in which workers travel-to-work and travel-for-work could offer important further 
contributions to our understanding of the increasingly complex routines of work-related travel. Nevertheless, the findings presented have a number of important implications for workplace and broader policy. Firstly, the evidence presented with respect to the commute, in particular, indicates that transport policy needs to focus on increasing the accessibility of public transport. In addition to existing concerns regarding the environment, the evidence in this article finds travel by car to be unproductive, stressful, and difficult to plan around due to unexpected delays. Second, given the propensity to work during travel, the evidence presented highlights the need for workplace policy which acknowledges elements of travelfor-work in workplace time accounts. More widespread use of TOIL by employers is required in acknowledgement of this time-use. Meanwhile, from a health and safety perspective, employers must offer greater acknowledgement of travel-for-work, which often creates intense schedules, in measures of work-time. Given the range of benefits for employer (business generation/retention) and employee (mobility capital, career development) derived from travel-for-work, it is important to facilitate better management alongside work and family/household.

\section{References}

Aguiléra, A. (2008). Business travel and mobile workers. Transportation Research Part A, 42(8), 1109-1116.

Basmajian, C. (2010). “Turn on the Radio, Bust out a Song”: the Experience of Driving to Work.

Transportation, 37(1), 59-84.

Bergman, A., Gustafson, P. (2008). Travel, availability and work-life balance. In Hislop, D. (ed.), Mobility and Technology in the Workplace, Routledge: Oxon, 192-208.

Bergström, G. (2006). Ett arbetsliv i rörelse. Resandets positiva och negativa potential för arbetstillfredsställelsen bland resande säljare. Arbetsmarknad \& Arbetsliv, 12(3), 147-60. 
Bergström Casinowsky, G. (2013). Working life on the move, domestic life at standstill? Work-related travel and responsibility for home and family. Gender, Work and Organization, 20(3), 311-326.

Black, I., Jamieson. S. (2007). Up, Up and Fading Away: The Work and Family Life of Executive International Travellers. Policy and Practice in Health and Safety, 5(2), 63-78.

Boell, S., Cecez-Kecmanovic, D., Campbell, J. (2016). Telework paradoxes and practices: the importance of the nature of work. New Technology, Work and Employment, 31(2), 114-131.

Bonache, J. (2005). Job satisfaction among expatriates, repatriates and domestic employees. Personnel Review, $34(1), 110-124$.

Chaloff, J., Lemaître, G. (2009). Managing Highly Skilled Labour Migration: A Comparative Analysis of Migration Policies and Challenges in OECD Countries. OECD Social, Employment and Migration Working Papers, No. 79, OECD Publishing.

Clark, W., Huang, Y., Withers, S. (2003). Does commuting distance matter? Commuting tolerance and residential change. Regional Science and Urban Economics, 33(2), 199-21.

De Vos, J., Schwanen, T., Van Acker, V., Witlox, F. (2013). Travel and subjective well-being: a focus on findings, methods and future research needs. Transport Reviews, 33(4), 421-442.

Diamond, L., Hicks, A., Otter-Henderson, K. (2008). Every Time You Go Away: Changes in Affect, Behavior, and Physiology Associated With Travel-Related Separations From Romantic Partners. Journal of Personality and Social Psychology, 95(2), 385-403.

Diener, E., Suh, E. M., Lucas, R. E., Smith, H. L. (1999). Subjective well-being: Three decades of progress. Psychological Review, 125, 276-302. 
Eriksson, L., Friman, M., Gärling, T. (2013). Perceived Attributes of Bus and Car Mediating Satisfaction with the Work Commute. Transportation Research Part A: Policy and Practice, 47, 87-96.

Espino, C.M., Sundstrom, S.M., Frick, H.L., Jacobs, M., Peters, M. (2002). International business travel: Impact on families and travellers. Occupational and Environmental Medicine, 59, 309-322.

Ettema, D., Friman, M., Gärling, T., Olsson, L.E., Fujii, S. (2012). How in-vehicle activities affect Work Commuters' Satisfaction with Public Transport. Journal of Transport Geography, 24, 215-222.

Felstead, A, N. (2012). Rapid change or slow evolution? Changing places of work and their consequences in the UK. Journal of Transport Geography, 21(1), 31-38.

Felstead, A, N., Jewson, N., Walters S. (2005). Changing Places of Work. London: Palgrave.

Global Business Travel Association (GBTA) (2016). GBTA BTI TM Outlook [online]. Available at: http://www.gbta.org/europe/Pages/default.aspx.

Green, A. E. (2004). Is Relocation Redundant? Observations on the Changing Nature and Impacts of Employment-related Geographical Mobility in the UK. Regional Studies, 38(6), August, 629-641.

Green, A.E., Berkeley, N. (2006). The West Midlands: the 'Hinge' in the Middle. In Hardill, I. et al (eds.), The Rise of the English Regions? London: Routledge.

Green, A. E. Owen, D. W. (2006). The Geography of Poor Skills and Access to Work. York: Joseph Rowntree Foundation.

Gripsrud, M., Hjorthol, R., (2012). Working on the train: from 'dead time' to productive and vital time. Transportation, 39(5), 941-956. 
Gustafson, P. (2006). Work-related travel, gender and family obligations. Work, Employment and Society, 20(3), 513-30.

Gustafson, P. (2012). Managing business travel: Developments and dilemmas in corporate travel management. Tourism Management, 33(2), 276-284.

Gustafson, P. (2012a). Travel time and working time: What business travellers do when they travel, and why? Time \& Society, 21(2), 203-222.

Gustafson, P. (2014). Business Travel from the Traveller's Perspective: Stress, Stimulation and Normalization. Mobilities, 9(1), 63-83.

Hardill, I., Bentley, C., and Cuthbert, M. (2006). The East Midlands: The Missing Middle? In Hardill, I. et al (eds.), The Rise of the English Regions? London: Routledge.

Hicks, S., Tinkler, L., Allin, P. (2013). Measuring subjective well-being and its potential role in policy: Perspectives from the UK Office for National Statistics. Social Indicators Research, 114(1), 73-86.

Hislop, D., Axtell, C. (2009), 'To Infinity and beyond? Workspace and the Multi-Location Worker', New Technology, Work and Employment, 24(1), 60-75.

Holley, D., Jain, J., Lyons, G. (2008). Understanding business travel time and its place in the working day. Time \& Society, 17(1), 27-46.

Jeong, Y-J., Zvonkovic, A., Sano, Y., Acock, A. (2013). The occurrence and frequency of overnight job travel in the USA. Work, Employment and Society, 27(1), 138-152.

Jones, A. (2013). Conceptualising business mobilities: Towards an analytical framework. Research in Transportation Business \& Management, 9, 58-66. 
Kahneman, D. Krueger, A.B., Schkade, D., Schwartz, N., Stone, A. (2004). Toward National Well-being Accounts. The American Economic Review, 94, 429-434.

Kloosterman, R.C. Musterd, S. (2001). The Polycentric Urban Region: Towards a Research Agenda. Urban Studies, 38(4), 623-33.

Koroma, J., Hyrkkänen, U., Vartiainen, M. (2014). Looking for people, places and connections: hindrances when working in multiple locations: a review. New Technology, Work and Employment, 29(2), 139-59.

Lassen, C. (2009). Networking, knowledge organizations and aeromobility. Geografiska Annaler: Series B, Human Geography, 91(3), 229-202.

Lu, J. L., Peeta, S. (2009). Analysis of the factors that influence the relationship between business air travel and videoconferencing. Transportation Research Part A, 43(8), 709-721.

Mahroum, S. (2000). Highly skilled globetrotters: mapping the international migration of human capital. $R \& D$ Management, 30(1), 23-32.

McQuaid, R., Chen, T. (2012). Commuting times - The role of gender, children and part-time work. Research in Transportation Economics, 34(1), 66-73.

Moktharian, P., Salomon, I. (2001). How derived is the demand for travel? Some conceptual and measurement considerations. Transportation Research Part A, 35(8), 695-719.

Nicholas, H., McDowall, A. (2012). When work keeps us apart: a thematic analysis of the experience of business travellers. Community, Work and Family, 15(3), 335-355.

Office for National Statistics (ONS) (2016). National Travel Survey, 2015 [online]. Available at: https://www.gov.uk/government/uploads/system/uploads/attachment_data/file/551437/national-travel-survey2015.pdf. 
Office for National Statistics (ONS) (2016). Travel Trends, 2015 [online]. Available at: http://www.ons.gov.uk/peoplepopulationandcommunity/leisureandtourism/articles/traveltrends/2015.

Ritchie, J. and Spencer, L. (2003). [eds] Qualitative Research Practice. London: Sage.

Roberts, J., Hodgson, R., Dolan, P. (2011). "It's driving her mad": Gender differences in the effects of commuting on psychological health. Journal of Health Economics, 30(5), 1064-76.

Roehling, P., Bultman, M. (2002). Does absence make the heart grow fonder? Work-related travel and marital satisfaction. Sex Roles, 46(9/10), 279-93.

Sandow, E. (2008). Commuting behaviour in sparsely populated areas: evidence from northern Sweden. Journal of Transport Geography, 16(1), 14-27.

Storme, T., Beaverstock, J., Derruder, B., Faulconbridge, J., Witlox, F. (2013). How to cope with mobility expectations in academia: Individual travel strategies of tenured academics at Ghent University, Flanders. Research in Transportation Business \& Management, 9, 12-20.

Stutzer, A., Frey, B. S. (2008). Stress that doesn't Pay: The Commuting Paradox. Scandinavian Journal of Economics, 110(2), 339-366.

Wheatley, D. (2012). Good to be home? Time-use and Satisfaction Levels among Home-based Teleworkers. New Technology, Work and Employment, 27(3), 224-41.

Wheatley, D. (2014). Travel-to-Work and Subjective Well-Being: A Study of UK Dual Career Households. Journal of Transport Geography, 39, 187-196.

Wheatley, D., Hardill, I., Philp, B. (2011). "Managing” reductions in Working Hours: A Study of Work Time and Leisure Preferences in UK Industry. Review of Political Economy, 23(3), 409-20. 
Wheatley, D. and Wu, Z (2014). Dual Careers, Time-Use, and Satisfaction Levels: Evidence from the British Household Panel Survey. Industrial Relations Journal, 45(5), 443-464. 
Table 1: Interviewee profiles

\begin{tabular}{|c|c|c|c|c|c|c|c|c|c|}
\hline $\begin{array}{c}\text { Interview } \\
\text { No. }\end{array}$ & Age & Gender & $\begin{array}{l}\text { Marital } \\
\text { status }\end{array}$ & $\begin{array}{l}\text { No. } \\
\text { Children }\end{array}$ & Occupation & Industry & $\begin{array}{c}\text { Main mode } \\
\text { of travel to } \\
\text { work } \\
\end{array}$ & $\begin{array}{c}\text { Average } \\
\text { commute } \\
\text { (in minutes) } \\
\end{array}$ & $\begin{array}{l}\text { Types of travel- } \\
\text { for-work }\end{array}$ \\
\hline 1 & 56 & Female & Cohabiting & 2 & Director & $\begin{array}{l}\text { Human } \\
\text { Resources }\end{array}$ & Car & 40 & Local \\
\hline 2 & 44 & Female & Cohabiting & 0 & $\begin{array}{l}\text { Finance } \\
\text { Manager }\end{array}$ & Manufacturing & Car & 105 & $\begin{array}{l}\text { Local, regional, } \\
\text { national (UK) }\end{array}$ \\
\hline 3 & 52 & Female & Married & 1 & $\begin{array}{l}\text { Company } \\
\text { Secretary }\end{array}$ & Construction & Cycle & 5 & Local, regional \\
\hline 4 & 38 & Male & Married & 2 & $\begin{array}{l}\text { Enterprise } \\
\text { Consultant }\end{array}$ & IT & Train & 150 & $\begin{array}{l}\text { Local, regional, } \\
\text { national (UK), } \\
\text { international }\end{array}$ \\
\hline 5 & 27 & Female & Single & 0 & Technologist & Engineering & Car & 45 & $\begin{array}{l}\text { Local, regional, } \\
\text { national (UK), } \\
\text { international }\end{array}$ \\
\hline 6 & 33 & Male & Married & 2 & $\begin{array}{l}\text { Company } \\
\text { Director }\end{array}$ & $\begin{array}{c}\text { Energy } \\
\text { Consultancy }\end{array}$ & Car & 25 & $\begin{array}{l}\text { Local, regional, } \\
\text { national (UK) }\end{array}$ \\
\hline 7 & 41 & Male & Married & 2 & $\begin{array}{l}\text { Assistant } \\
\text { Director }\end{array}$ & $\begin{array}{l}\text { Education } \\
\text { Charity }\end{array}$ & Car & 45 & $\begin{array}{l}\text { Local, regional, } \\
\text { national } \\
\text { (England) }\end{array}$ \\
\hline 8 & 33 & Male & Married & 3 & $\begin{array}{l}\text { Finance } \\
\text { Manager }\end{array}$ & $\begin{array}{l}\text { Higher } \\
\text { Education }\end{array}$ & Car & 15 & $\begin{array}{l}\text { Local, regional, } \\
\text { national (UK), } \\
\text { international }\end{array}$ \\
\hline 9 & 51 & Female & Married & 0 & $\begin{array}{l}\text { Partnership } \\
\text { Manager }\end{array}$ & $\begin{array}{c}\text { Local } \\
\text { Government }\end{array}$ & Bus & 45 & Local, regional \\
\hline 10 & 32 & Male & Cohabiting & 1 & $\begin{array}{c}\text { Lecturer / } \\
\text { Academic } \\
\text { Management }\end{array}$ & $\begin{array}{l}\text { Higher } \\
\text { Education }\end{array}$ & Train & 90 & $\begin{array}{l}\text { Local, regional, } \\
\text { national (UK), } \\
\text { international }\end{array}$ \\
\hline 11 & 39 & Male & Married & 2 & $\begin{array}{l}\text { Finance } \\
\text { Manager }\end{array}$ & Consultancy & Car & 30 & $\begin{array}{l}\text { Local, regional, } \\
\text { national (UK) }\end{array}$ \\
\hline 12 & 34 & Female & Married & 1 & $\begin{array}{c}\text { Audit } \\
\text { Manager }\end{array}$ & Engineering & Car & 60 & $\begin{array}{l}\text { Local, regional, } \\
\text { national (UK), } \\
\text { international }\end{array}$ \\
\hline 13 & 57 & Female & Married & 0 & Analyst & $\begin{array}{c}\text { Local } \\
\text { Government }\end{array}$ & Walk & 40 & Local \\
\hline 14 & 46 & Male & Cohabiting & 0 & $\begin{array}{l}\text { Principal } \\
\text { Lecturer }\end{array}$ & $\begin{array}{l}\text { Higher } \\
\text { Education }\end{array}$ & Train & 90 & $\begin{array}{l}\text { Local, regional, } \\
\text { national (UK) }\end{array}$ \\
\hline
\end{tabular}


Table 2: Mean impacts of work-related travel on aspects of life

\begin{tabular}{|c|c|c|c|c|c|c|}
\hline \multirow[b]{2}{*}{$\begin{array}{l}\text { Commute time } \\
\text { (minutes) }\end{array}$} & \multicolumn{5}{|c|}{ How does your commute impact the following aspects of your life? } & \multirow[b]{2}{*}{$\mathbf{n}$} \\
\hline & Career & Time-use & Family & Health & $\begin{array}{c}\text { Overall } \\
\text { happiness }\end{array}$ & \\
\hline $1-30$ & $3.48(1.205)$ & $3.54(1.475)$ & $3.72(1.381)$ & $3.78(1.360)$ & $4.02(1.432)$ & 85 \\
\hline $31-60$ & $3.05(0.639)$ & $2.30(1.137)$ & $2.55(1.131)$ & $3.00(0.987)$ & $2.78(1.187)$ & 41 \\
\hline Over 60 & $3.60(1.454)$ & $2.07(1.335)$ & $1.93(0.704)$ & $2.73(1.100)$ & $2.60(0.910)$ & 15 \\
\hline Total & $3.37(1.114)$ & $3.01(1.505)$ & $3.18(1.419)$ & $3.43(1.298)$ & $3.50(1.456)$ & 141 \\
\hline \multirow[t]{2}{*}{ Correlation coeff. } & 0.040 & $-0.395 * * *$ & $-0.472 * * *$ & $-0.309 * * *$ & $-0.373 * * *$ & \\
\hline & \multicolumn{5}{|c|}{ How does your travel-for-work impact the following aspects of your life? } & \\
\hline \multicolumn{7}{|c|}{ Frequency of travel } \\
\hline Less than monthly & $3.38(0.794)$ & $2.76(0.760)$ & $2.83(0.609)$ & $2.95(0.524)$ & $3.03(0.600)$ & 43 \\
\hline Monthly & $3.59(0.654)$ & $2.87(0.862)$ & $2.80(0.650)$ & $2.91(0.586)$ & $3.16(0.714)$ & 63 \\
\hline Weekly & $3.61(0.761)$ & $2.74(0.815)$ & $2.55(0.810)$ & $2.87(0.670)$ & $3.10(0.790)$ & 35 \\
\hline Correlation coeff. & 0.094 & -0.094 & $-0.154 *$ & -0.097 & -0.032 & \\
\hline \multicolumn{7}{|c|}{ Nights away in past 12 months } \\
\hline $0-5$ & $3.39(0.695)$ & $2.80(0.872)$ & $2.87(0.703)$ & $3.03(0.567)$ & $3.19(0.665)$ & 103 \\
\hline $11-30$ & $3.81(0.680)$ & $2.81(0.680)$ & $2.65(0.671)$ & $2.71(0.561)$ & $3.05(0.669)$ & 24 \\
\hline Over 30 & $4.17(0.577)$ & $3.00(0.853)$ & $2.17(0.577)$ & $2.50(0.798)$ & $2.67(0.888)$ & 14 \\
\hline Correlation coeff. & $0.364 * * *$ & 0.076 & $-0.280 * * *$ & $-0.296^{* * *}$ & $-0.210 * *$ & \\
\hline Total & $3.54(0.725)$ & $2.82(0.837)$ & $2.76(0.714)$ & $2.93(0.614)$ & $3.11(0.701)$ & 141 \\
\hline \multicolumn{7}{|c|}{$\begin{array}{l}\text { Source: Travel-for-Work Research Project } 2015 \\
\text { Notes: A mean of less than } 3 \text { is indicative of more negative impacts, and above } 3 \text { more positive impacts. Standard } \\
\text { deviations shown in parentheses. }\end{array}$} \\
\hline
\end{tabular}

